\title{
Wailing More than the Bereaved: Afrocentric Reflections on Gender Issues in Shona Traditional Religion and Culture
}

\section{Beatrice Taringa}

\begin{abstract}
Gender issues in the context of African culture and religion have been explored from a Western liberal feminist approach. This approach, assuming Western ontology and epistemology, approach gender issues with pre-set categories that indicate that African women are oppressed. As a result, the main argument has been that the relationship between males and females serves to divide, oppose and alienate females from males. So, even African feminists who have attempted to address gender issues in African culture and religion tend to produce Western research on gender issues done by indigenous people. To this end, they also end up wailing more than the bereaved regarding the status of African women in terms of gender. They end up giving an outsider perspective, like a stranger who upon arriving at a funeral and wails more than the bereaved and later asks, 'Who has died?' Therefore, the central questions in this paper are (i) are Shona women oppressed? (ii) is there a framework that can be used to account for gender issues in Shona communities in their own terms? This paper explores Shona ontology as an indigenist research paradigm to account for gender issues in Shona culture and religion. The paper argues that the relationship between males and females in Shona culture and religion must be understood in the context of a truly relational ontology where all things are recognized and respected for their place in the overall system. While males and females are differentiated, their relationships are neither oppositional nor binary, but inclusive and accepting diversity.
\end{abstract}

Keywords: gender, ontology, relational, indigenist paradigm, feminist 


\section{Introduction and Background}

The main question in this paper is how we might account for, or explain gender issues in African communities and in particular in Shona traditional religion and culture. Most scholars on gender issues in African communities have tended to account for and analyse gender issues in the light of Western feminist theoretical frameworks, in particular Western liberal feminist theoretical perspectives. For example, the different forms of gender bias that may be found in literature texts have been considered in terms of Sadker and Sadker's (2001) pre-set categories of invisibility, stereotyping, linguistic unreality, fragmentation, selectivity, and cosmetic biases. This is consistent with their research questions, which tend to point to gender issues picked through pre-set categories already encompassed in Western feminist theories. Rarely do we find cases where gender issues are regarded as affirming the African male and African female relational ontology. In order for this research to build in openness to the unexpected, to new findings, it employs an interpretive theoretical framework using an Afrocentric perspective, particularly Africana womanism. This article therefore departs from Western feminist approaches to gender issues in African communities and employs an Afrocentric theory called Africana womanism in order to account for and analyse gender issues in their own terms; that is in the context of the Shona culture which the authors presuppose.

\section{Afrocentrism}

Afrocentrism is a complex concept. It defies a single and simple definition. Mazama (2003: 5) notes,

There is still confusion on the definition of the term Afrocentricity as some scholars tend to give their own definitions, free versions and often choosing to emphasize on certain aspects of the paradigm to suit their own purposes. Others take term Afrocentricity for granted and ignoring to define it.

It is not the intention of this paper to settle the definitional problems related to Afrocentrism. Afrocentrism is rather complex. It has many manifestations and expressions. As a result, this study is going to settle for the common characteristics of the Afrocentric perspective, particularly as espoused in definitions by leading scholars such as Asante, and settles for choosing to em- 
phasize certain aspects of the paradigm to suit the purpose of this study.

One way in which Afrocentrism is defined is with reference to the establishment of a particular frame of reference and as an intellectual theory. For example, Asante (1991: 172) tells us that Afrocentrism establishes,

A frame of reference wherein phenomena are viewed from the perspective of the African person ... it centres on placing people of African origin in control of their lives and attitudes about the world. This means that we examine every aspect of the dislocation of African people; culture, economies, psychology, health and religion .... As an intellectual theory, Afrocentricity is the study of the ideas and events from the standpoint of Africans as the key players rather than victims. The theory becomes, by virtue of an authentic relationship to the centrality of our own reality, a fundamentally empirical project ... it is the African asserting itself intellectually and psychologically, breaking the bonds of western domination in every other field.

An important implication of this definition is, as Mazama (2003: 5) rightly points out,

Afrocentricity, contends that our main problem is precisely, ours, usually unconscious, adoption of the Western worldview and perspectives and their attendant conceptual framework. The list of those ideas and theories that have invaded our lives as 'normal', 'natural' or even worse, 'ideal', is infinite.

The scholar further contends that, 'Rarely would people question concepts like 'the need for democracy', planning, progress, the nation state as the best form of political and social organization, to name only a few'. One of the concepts that have not been questioned in relation to gender issues in Shona traditional religion and culture is the liberal feminist approach. as conceptual framework.

In order to desist from adoption of the Western worldview and perspectives and their attendant conceptual frameworks. this study takes heed of Asante's call for the need for an Afrocentric orientation towards data. This involves, in the case of this study, a way of analysing information from an African Shona perspective, as opposed to from a Western feminist perspective. The central issue is: How would Africans look at gender issues if there was no 
Western feminism? To continue using Western gender-perspective means, according to Afrocentric terminology,

we do not exist in our own terms, but on borrowed terms, European ones. We are dislocated and having lost sight of ourselves in the midst of European decadence and madness, it becomes increasingly difficult for us to orient our lives in a positive and constructive manner, hence the plight that is ours.

Mazama (2003: 5) sums this up by saying,

The challenge is monumental: our liberation, Afrocentricity contends, rests upon our ability to systematically displace European ways of thinking, being, feeling, etc. and consciously replace them with ways that are germane to our own African cultural experience.

This article therefore assumes that gender means different things to different people since it carries the ideologies of the sociocultural context within which it is constructed (Gambahaya, Muwati \& Mutasa 2008: 41). Therefore, the focus is on reflecting the possibility of an indigenist paradigm for accounting for the state of gender relations in Shona traditional religion and culture. In this way this paper argues for different points of departure in order to understand gender issues among the Shona by taking Shona views of reality (ontology) as a starting point. We are encouraged more than before, in the light of Afrocentrism, to rely on local perspectives to measure our African phenomena and gender issues should not be an exception. Thus, the current study argues for Afrocentric paradigm, in particular its branch called Africana womanism.

\section{Africana Womanism}

Africana Womanism, like Afrocentrism, is a broad-based theoretical perspective. It accommodates several motifs, if not species, under its genius. No definition or shortlist of characteristics could be exhaustive, but many, although by no means all, Africana womanism theories are able to identify their perspective with the idea that Africana womanism proceeds from the proposition that relations expressed in African culture, and in my case in Shona culture, need to be taken seriously, and shall be considered in their own terms. 
This paper therefore differs from liberal feminist approaches that premise gender issues on the philosophy of Western individualism and tends to describe such gender relationships as massive gender oppression, gender stereotyping, gender bias and gross human rights violation. The strength of Africana womanism is therefore that it assumes that African gender relationships must be grounded in distinctive ontologies and epistemologies characterized by a holistic approach in which male and female constitute an organic reality.

This is why Hudson-Weems (2003: 157) argues that Africana Womanism is,

neither an outgrowth nor an addendum to feminism, or Walker's womanism that some Africana woman has come to embrace. It is an ideology created and designed for all woman of African descent. It is grounded in African culture and, therefore, it necessarily focuses on the unique experiences, struggles, needs and desires of African women.

We therefore agree with Gambahaya et al. (2008), who find it quite disturbing to continue using Western feminist approaches when dealing with gender issues in Africa. They note,

Quite disturbing, though, is the fact that in many instances today, women's studies in particular and gender studies in general continue to be directed and informed by western feminist ontologies, as if they are a naturalized reality in a multicultural context.

Gambahaya et al. (2008:41) decry Western feminism as an approach that has fundamentally eclipsed the African gender possibility, which in many ways has nothing in common with the Western view with its insatiable inclination towards polarization. What is more important for this paper is the way the position they argue for is consistent with Africana womanism. They rightly point out the thrust of Africana womanism when they say,

The thrust is on casting a different gender ontology that taps from African ontological and epistemological experience; it should occur that it is natural and legitimate for any people to approach their life from the perspective of their own culture. 
In this article I will take the issue of ontology further and qualify it as Shona relational ontology. I will explain this at the end of this section.

Hudson-Weems (2003: 153) shares the same concern. The scholar finds Western feminism embarrassing. He regards feminism as 'an embarrassing Western philosophy'. He therefore discredits feminism as the destroyer of homes that were imported from America to ruin nice African women (Ama Ata Aidoo, 1999) and insists that the African context needs to consider the role of African women and her family, her community and her career in today's society as the central question. In approaching gender issues this paper does not assume that gender issues in Shona culture primarily involve seeing men as the primary enemy of women. I therefore agree with Hudson-Weems (2003: 158) who argues that

first, Africana woman does not see man as her primary enemy as does the white feminist, who is carrying an age battle with her white male counterpart for subjugating her as property. Africana men have never had the same institutionalized powers as to oppress Africana women as white man has had to oppress white women'.

Theoretically my point of departure is therefore that gender issues in the context of African culture have been explored from a Western liberal feminist approach. This approach, assuming Western ontology and epistemology, approach gender issues with pre-set categories that indicate that African women are oppressed. As a result, the main argument has been that the relationship between males and females serves to divide, oppose and alienate females from males. This is because the philosophical basis of liberal feminism is individualism. Even African feminists who have attempted to address gender issues in African culture, tend to produce Western research on gender issues done by indigenous people. To this end, they also end up wailing more than the bereaved regarding the status of African women in terms of gender. They end up giving an outsider perspective, like a stranger who upon arriving at a funeral and wails more than the bereaved and latter asks, 'Who has died?'

This article employs African womanism grounded in Shona relational ontology as an indigenist research paradigm to reflect on the context in which gender issues in Shona communities must be considered. In using Africana womanism as theoretical framework we argue that the relationship between males and females in Shona culture must be understood in the context of a truly 
relational ontology where all things are recognized and respected for their place in the overall system. While males and females are differentiated, their relationships are neither oppositional nor binary, but are inclusive and accepting diversity. We assume Gambahaya et al.'s (2008:41) observation that, the Shona and Ndebele conception of gender means 'different things to different people since it carries the ideologies of the socio-cultural context in which it is constructed'.

I therefore argue that the ontology and personhood embedded in Western feminist discourses on gender are not universal. Gender issues in Shona communities must be approached against the backdrop of Africana womanism featuring Shona, relational ontology. In Shona context, gender does not necessarily imply asymmetrical dualism that characterizes Western feminist discourse regarding gender issues in African contexts. It might be that our gender data are groaning, being forced into pre-set Western feminism gender categories.

\section{Wailing More than the Bereaved: Position of Women a Little Lower than a Slave}

Many scholars influenced by Western feminism mourn the position of women in traditional African society. Among the Shona in Zimbabwe, Owomoyela (2002: 91-92), who observes that,

Men and women had well-defined roles and obligations that were specific and exclusive to their respective genders. The division of labor was such that the domestic sphere, on the one hand, belonged to the woman, and there her authority was unchallenged; the public domain, on the other hand, belonged to the man. Neither arena was regarded as superior to the other. The woman had the responsibility of distributing food and managing household affairs. Women also did work outside the home. They did most of the lighter work on the farm like planting and weeding. Heavier work like felling trees and cleaning the land fell to men. Husband cuts the poles, and builds and thatches the hut. He builds also the bakwa (wood storage area). He makes the bark sacks and the baskets such as dengu and misero. He makes reed sleeping mat and pillow of wood. He makes hoe handles axe shafts and bow; also, wooden plates, spoons and porridge sticks. 
He makes drums, spears. He hunts, milks and he is also the butcher and skinner. As for the woman she makes the inside of the huts, jugs, pots, cuts roofing grass, cooks food, draws water, grinds the meal, catches white ants and caterpillars.

In light of this observation the conclusion is that women have little or no status. The reasons are given in various directions. The most common reasons are summarized by Bourdillon (1987: 50) when he writes,

there are many reasons given for this view: women are said to be bought and sold in marriage like chattels; at the death of a husband, his widows are inherited with his estate; since women could not represent themselves in traditional courts but had to be represented by a senior male relative, it is said legally they were minors all their lives; wives are said to be completely subject to their husbands who have the right to beat them within limits; women do most of the work in the fields and in the home while men spend much of their time sitting in idle chatter. So, some conclude that the traditional position of Shona women is a little better than the position of a slave.

The conclusion indicated in this quotation summarizes the findings reached by many Western feminist-oriented treatments of gender issues in African communities. They leave us with gender analyses based on an ontology that is trapped in a Cartesian 'subject-object' relation. Gender issues in African societies and in particular Shona society must be approached in the context of Shona relational ontology featuring, kinship, hunhu, opposites as sides of the same coin, sanctity of the individual as not the highest moral good and all is one and all is well.

\section{Relational Ontology: Kinship}

At the heart of Shona people are kinship. Mbiti's (1970: 135) observation about in kinship among Africans in general is apt and therefore worth quoting at length. He notes that:

Kinship is reckoned through blood and betrothal (engagement and marriage). It is kinship which controls social relationships between 
people in a given community: it governs marital customs and regulations; it determines the behavior of one individual towards another. Indeed, this sense of kinship binds together the entire life of the tribe and is even extended to cover animals, plants, and non-living objects through the totemic system. Almost all the concepts connected with human relationships can be understood and interpreted through the kinship system. This it is which largely governs the behavior, thinking, and whole life of the individual in the society of which he is a member.

This idea of kinship is based on the belief that all people are descended from a common ancestor who long ago lived in their territory (Paris, 1995:77). The status of women vis a vis men in Shona society must therefore primarily be considered in the context of kinship. In this context, the key word is relationship; in fact, ontological relationship. The Shona views the world in such a way that everything in the universe is due to relationships. Everything is interconnected, interwoven, one; everything can relate to us and we can relate to every 'thing' as one. Therefore, relations between males and females are more fundamental than the males and females themselves. This flies in the face of substantivism ontology, which implies that males/females are ontologically primary and relations ontologically derivative (Wildman, 2006:1). The ontological primacy of relations is emphasized in Shona hunhuism.

\section{Hunhu and Nested Relatedness}

At the heart of Shona traditional religio-culture is hunhu. Hunhu expresses and promotes an ethic of kinship between human beings and other forms of life; plant and biological. Hunhu turns attention to we-ness. Hunhu is against the individualistic framing of male and female as discrete individuals. They have the following wisdom sayings, 'Rume rimwe harikombi churu, Chara chimwe hachitswanyi inda, Kutsva kwendebvu varume vanodzimurana (At the heart of hunhu stands a relationality which frames males and females as 'nested relatedness).' Hunhu is not premised on the dichotomous opposition of culture and nature. Hunhu privileges knowing how to behave within relations in order to nourish these relations more than knowing things in and for themselves as objects separate from the knower. Based on the relational personhood concept hunhu fosters a relational perception of husbands and wives. 
Hunhu does not take the axiomatic biological split between husbands and wives as essential. The Shona person is a composite of relationships. The person is conceived of as dividual and not individual. The Shona is misrepresented if depicted as an individual. The person has a holistic collective identity. Gender in Shona is relational, premised on personhood regarded as dividual rather than individual. In essence, dividual means a person is constitutive of relationships. The issues are how one relates to others, and part of the others is the female, conscious of relatedness. So, there is consciousness of relatedness. The central idea is that one shares space, things, and actions with others. There is a strong sense of sharing with others vs distribution of rights. The Shona people address each other by kinship terms: baba, mai, Mbuya, Sekuru, muzukuru, mainini, tezvara, mwana, mukoma, munin'ina, hanzvadzi, tete, and also totems (Dziva, Shumba, Tembo, etc.). The Shona therefore do not, in their conception of gender, through hunhu, individuate but dividuate husband and wife in their relationship. They are attentive to, and work, towards making relatedness. The Shona not only share relationships with fellow Shona, but also with members of other species in the vicinity. They make their personhood by producing and reproducing sharing relationships with surrounding beings; humans and others. They do not dichotomize other beings vis-a-vis themselves but regard them, while differentiated, as nested within each other (Mudzimu weshiri uri mudendere). They therefore appreciate that husbands and wives share responsibilities and not rights. They emphasize a one we-ness, the heart of hunhu; 'we are because we are'. There is a 'we-ness' versus 'sameness'.

For past centuries gender issues in African cultures have been hijacked by a Western worldview and have been interpreted from a Western feminist perspective in order to maintain the individualism at the heart of Western culture. The 'I' in the often cited 'I am because we are' is not the primary axis of hunhu. The 'I am' is a smuggled Western individualism. The correct rendering is 'we are because we are'. This is consistent with Shona culture where the primary unit of the society is not the individual.

\section{Opposite Sides of the Same Coin}

An African is never regarded as a loose entity to be dealt with strictly individually (so the idea of exclusion/inclusivity does not arise). His being is based on, or coupled with that of others. Next to - or behind - or in front of him there is always someone through whom he is associated. The concepts of 
plurality and belonging to are always present, e.g. a person is always viewed as 'Motho aw batho' (person of person or belonging to persons) or 'Motho weso' (our person of person that is ours) (Paris 1995: 101).

First and foremost, of course the African person is defined as a member of a family, and so the African person is never alone in self-concept or in the perception of others. In fact, one can rightly claim that the African person is related to the family as the part of a living organism is related to the whole. As the former cannot live apart from the latter, so the life of a person is wholly dependent on the family and its symbiotic functions of biological lineage, communal nurture, and moral formation (Paris 1995:101).

Whatever happens to the individual happens to the whole group, and whatever happens to the whole group happens to the individual. The individual can only say: 'I am because we are: and since we are, therefore I am. This is a cardinal point in the understanding of the African view of man.' (Paris 1995: 111). In short, it means we are because we are. The Shona person is dividual rather than individual.

This is difficult for Western minds to grasp; Africans have no conception of a person apart from a community. This means more than the maintenance of a symbiotic relation between the individual and the community. Such implies a prior separate state. No such separation is possible in African thought. The two are related as opposite side of the same coin. The one implies the other (Paris 1995: 111).

\section{The Sanctity of the Individual Person not the Highest Moral Good}

Traditional African cultures are ordered in accordance with the principle of community that was hierarchically arranged, with the community of ancestors as the primary ruling power, followed by the descending authorities of tribal and familial communities respectively. The African person can only be understood in that tripartite communal relation. Interdependent relations among persons, families, tribe, and ancestors comprise the nature of African humanity. Since each is a part of a whole, all are related to one another reciprocally. That is to say, the purpose of each is to contribute to life and to receive life from all the others. No one community can exist severed from the others. In other words, each part of the whole social organism is necessary. As the value of the individual derives from the community, the goal of the community is to pro- 
mote the life of the individual. Thus, individual rights and liberties cannot be determined apart from this communal context and the necessary responsibilities and obligations implied by membership to it (Magesa 1997: 114).

This type of thinking is difficult for the Western mind to appreciate, because the latter alters the relation by giving primacy to individual persons and lesser value to either the family or the larger community. Such thought virtually reverses the African understanding of the relation of person and community. Much of Western society has tended to view the sanctity of the individual person as the highest moral good (Magesa 1997: 114).

\section{All is One and All is Well: Lessons from Taoism}

Taoism is tied to the traditional Chinese yin/yang symbol. The symbol is usually pictured as summing up all of life's basic oppositions: good/ evil, active/ passive, positive/ negative, light/ dark, summer/ winter and male/ female. Although the halves are in tension, they are not flatly opposed; they complement and balance each other. Huston (1991:214-215) explains the balance and complementarity as follows:

Each invades the other's hemisphere and takes up its abode in the deepest recess of its partner's domain. And in the end, both find themselves resolved by the circle that surrounds them, the Tao in its eternal wholeness, the opposites appear as no more than phases in an endless cycling process, for each turn incessantly into its opposite, exchanging places with it. Life does not move onward and upward toward a pinnacle or a pole. It bends back upon itself to come, full circle, to the realization that all is one and all is well.

This shows that Taoism eschews all sharp dichotomies. This way of looking at reality is consistent with the Shona traditional religio-cultural beliefs. Through Western ontology, Western feminist interpretations have tended to dichotomize male and female. After all, who knows what is good or bad? The major problem is,

If a conceptual framework that assumes gendering is fundamental social distinction, as evidently is the case in Western society, and is used to 'understand' a society in which gendering is not of such funda- 
mental importance, obviously misrepresentation and misunder-standing will result (Hallen, 2002: 106).

It may be that among some traditional Shona families each individual person accepts his or her sexuality and gender roles with grace and ease, without any undue embarrassment.

\section{Conclusion}

This paper has explored Shona ontology as an indigenist research paradigm for accounting for gender issues in Shona culture and religion. This is done against the backdrop of a strong distaste for Western liberal feminist approaches. The paper decries this type of Western feminism for championing the view that gender issues in African communities serve to divide, oppose and alienate females from males. In light of this the paper has likened Western feminism to a stranger who upon arriving at a funeral and wails more than the bereaved and latter asks, 'Who has died?' The paper has argued that the relationship between males and females in Shona culture and religion must be understood in the context of a truly relational ontology where all things are recognized and respected for their place in the overall system. It has highlighted the key components of Shona relational ontology framework as kinship, hunhu, opposites as sides of the same coin, sanctity of the individual as not the highest moral good and all is one and all is well. In this context it may be possible to view males and females as differentiated, their relationships being neither oppositional nor binary, but inclusive and accepting diversity. Since the paper has remained much at the theoretical level, future studies may need to test this alternative framework against qualitative data regarding how gender issues are being experienced in Shona communities.

\section{References}

Aidoo, A.A. 1999. Unwelcomed Paws and Decorative Slaves or Glimpses of Women as Writers and Characters in Contemporary African Literatures. Trenton: Africa World Press.

Asante, M.K. 1991. Afrocentricity: The Theory of Social Change. Revised and Expanded. New York: Armlefi. 
Asante, M.K. 1998. The Afrocentric Idea. Revised and Expanded Edition. Philadelphia: Temple University.

Bourdillon, M.F.C. 1987. The Shona Peoples: An Ethnography of the Contemporary Shona with Special Reference to their Religion. Gweru: Mambo Press.

Bourdillon, M.F.C. 1997. Where are the Ancestors? Changing Culture in Zimbabwe. Harare: University of Zimbabwe Publications.

Gambahaya, Z., I. Muwati \& D. Mutsa 2008. Restructuring the Gender

Conceptual Matrix from an African-centered Perspective: Repudiating the Feminist Ontology. Zambezia 35,i/ii: 40 - 51.

Hallen, B. 2002. A Short History of African Philosophy. Indiana: IUP.

Hudson-Weems, C. 2003. Africana Womanism. In Mazama A. (ed.): The

Afrocentric Paradigm. Trenton: Africa World Press, Inc.

Huston, S. 1991. The World's Religions: Our Great Wisdom Traditions. New

York: Harper San Francisco.

Magesa, L. 1997. African Religion: The Moral Traditions of Abundant Life.

Nairobi: Paulines Publications Africa.

Mazama, A. 2003. An Afrocentric Approach to Language Planning. In Mazama A. (ed.): The Afrocentric Paradigm. Trenton: Africa World.

Mbiti, J.S. 1970. African Religions and Philosophy. New York: Doubleday.

Owomoyela, O. 2002. Culture and Customs of Zimbabwe. London: Greenwood.

Paris, P.J. 1995. The Spirituality of African Peoples: The Search for a Common Moral Discourse. Minneapolis: Fortress Press.

Sadker, D. \& M. Sadker 2001. Gender Bias: From Colonial America to Today's Classroom. In Banks J.A. \& C.A.M. Banks (eds.): Multicultural Education: Issues and Perspectives. New York: John Wiley and Sons. Wildman, W.J. 2006. An Introduction to Relational Ontology. Available at: www.wesleywildman.com/.../2010-wildman-introduction-to-relational ontology (Accessed 12 July 2015).

Beatrice Taringa Research Methods and Indigenous Languages Department of Professional Studies Belvedere Technical Teachers' College Harare, Zimbabwe taringabeatrice@gmail.com 